\title{
A Study of Reliability and Validity for the Turkish Version of Dizziness Handicap Inventory
}

\section{Baş Dönmesi Engellilik Envanterinin Türkçe Geçerlilik ve Güvenilirlik Çalışması}

\author{
Metin Canbal $^{1}$, Sevsen Cebeci ${ }^{1 *}$, Gülsüm Çamur Duyan ${ }^{2}$, Hanefi Kurtaran $^{3}$, Ismail Arslan $^{4}$
}

\begin{abstract}
Objective: Dizziness is one of the most frequently seen unresolved diseases in primary health care. Regardless of its reason or characteristics; effects of dizziness in patients' daily life are very significant. This study is planned to adapt the Dizziness Handicap Inventory to Turkish and to use it in practice; an inventory which can be used to determine the alterations in the life qualities of the outpatients or inpatients consulted with the dizziness complaint. Method: 178 patients were included in the study, who was admitted to Turgut Ozal University Medical Faculty Otorhinolaryngology and Family Physician polyclinics with dizziness complaint for last 1 month. A semi-structured interview form and Dizziness Disability Inventory were used as data collection means. Results: Dizziness Disability Inventory; consists of 25 clauses which determine the aggravating factors associated with dizziness and shakiness and also the emotional and functional results of vestibular system diseases. The inventory consists of 3 sub-dimensions, intended to determine physical, emotional and functional effects of the vestibular system diseases. All of the sub-dimensions have high internal-confidence and their Cronbach Alfa values are between 0,67 and 0,82 . Also the Cronbach Alfa values of the sub-inventory groups were similar with the general inventory. Conclusion: The findings obtained from the study show that this inventory may be used on dizziness patients in Turkey, and it has satisfactory validity and reliability coefficients. It may be concluded that, by using this inventory, dizziness complaint and its effects on life quality can be monitored via more objective criteria.
\end{abstract}

Key words: Dizziness, quality of life, family practice

\section{ÖZET}

Amaç: Birinci basamakta en çok karşımıza çıkan ayrışmamış hastalık durumlarından biri, baş dönmesidir. Sebebi ve karakteristiği her ne olursa olsun baş dönmesinin hastaların günlük yaşamlarına olan etkisi oldukça önemlidir. Bu çalışma; baş dönmesi yakınması ile başvuran, ayaktan ya da yatarak tedavi edilen hastaların yaşam kalitelerindeki değişikliği belirlemede kullanılabilecek Baş Dönmesi Engellilik Envanterinin (Dizziness Handicap Inventory), Türkçeye uyarlanması ve pratikte kullanılması amacıyla planlanmıştır. Yöntem: Çalışmaya Turgut Özal Üniversitesi Tıp Fakültesi Kulak Burun Boğaz ve Aile Hekimliği Polikliniklerine son bir aydır devam eden baş dönmesi yakınması ile başvuran 178 hasta dahil edilmiştir. Veri toplama araçları olarak yarı yapılandırılmış görüşme formu ve Baş dönmesi Engellilik Envanteri kullanılmıştır. Bulgular: Baş Dönmesi Engellilik Envanteri, hastaların baş dönmesi ve denge bozukluğu ile ilgili ağırlaştırıcı faktörlerin yanı sıra vestibüler sistem hastalıklarında duygusal ve fonksiyonel sonuçları belirleyen 25 maddeden oluşmaktadır. Envanter, vestibüler sistem hastalıklarının fiziksel, duygusal ve fonksiyonel etkilerini belirlemeye yönelik üç alt envanter içermektedir. Tüm alt envanterlerin iç güvenirlikleri yüksek ve Cronbach alfa değerleri 0,67 ile 0,82 arasındadır. Envanterin genelinde olduğu gibi alt envanter gruplarından elde edilen Cronbach alfa değerlerinde de paralellik saptanmıştır. Sonuç: Elde edilen bulgular, envanterin ülkemizde baş dönmesi hastalarında kullanılabileceğini, yeterli düzeyde geçerlik ve güvenirlik katsayılarına sahip olduğunu göstermektedir. Bu envanterin kullanımı ile birlikte baş dönmesi yakınmasının ve yaşam kalitesine olan etkisinin daha objektif kriterlerle izlenebileceği düşünülmektedir.

Anahtar kelimeler: Baş dönmesi, yaşam kalitesi, aile hekimliği

Received / Geliş tarihi: 16.08.2015, Accepted / Kabul tarihi: 02.11. 2015

${ }^{1}$ Turgut Özal Üniversitesi Tıp Fakültesi Aile Hekimliği Anabilim Dalı, Ankara, ${ }^{2}$ Turgut Özal Üniversitesi Sağlık Yüksekokulu Sosyal Hizmet Bölümü, Ankara, ${ }^{3}$ Turgut Özal Üniversitesi Tıp Fakültesi Kulak Burun Boğaz Anabilim Dalı, Ankara, ${ }^{4}$ Ankara Eğitim ve Araştırma Hastanesi Aile Hekimliği Kliniği, Ankara. *Address for Correspondence / Yazışma Adresi: Sevsen Cebeci, Turgut Özal Üniversitesi Tıp Fakültesi Aile Hekimliği Anabilim Dalı, Ankara- TÜRKIYE, E-mail:cebecisevsen@ hotmail.com

Canbal M, Cebeci S, Duyan GÇ, Kurtaran H, Arslan İ. Baş Dönmesi Engellilik Envanterinin Türkçe Geçerlilik ve Güvenilirlik Çalışması. TJFM\&PC,

2016;10(1):19-24. DOI:10.5455/tjfmpc.198514 


\section{GíRiş}

Aile hekimliği disiplininin kendi bilimsel alanına özgü kavramlardan biri de ayrışmamış hastalık terimidir. Ayrışmamış hastalık; hastanın ilk kez doktor karşısına çıktı̆̆ 1 ve mevcut yakınmasının hastalıkların sınıflandırılması için tanımlanan herhangi bir hastalık sınıfına koyulamadığı durumları tanımlamak için kullanılır. ${ }^{1}$ Birinci basamakta sık karşılaşılan ayrışmamış hastalık durumlarından biri, baş dönmesidir. Baş dönmesi yakınması ile hastalar aile hekimliği, kulak burun boğaz (KBB) ve nöroloji polikliniklerine başvurmaktadırlar. Baş dönmesinde subjektif duyumlar ön plana çıkabilmektedir. Hastalar bu durumu tarif ederken "etraf dönüyor, yer ayağımın altından kayıyor, dengem bozuk, başımda hafiflik var" gibi ifadeleri kullanabilirler.

$\mathrm{Bu}$ çalışma; baş dönmesi yakınması ile başvuran ayaktan ya da yatarak tedavi edilen hastaların yaşam kalitelerindeki değişikliği belirlemede kullanılabilecek Baş Dönmesi Engellilik Envanterinin (BEE), Türkçeye uyarlanmas1 ve pratikte kullanılması amaciyla planlanmıştır. Şimdiye kadar orijinali olan İngilizcesinden başka birçok dile çevrilerek klinik kullanıma sunulan BEE, vestibüler sistem hastalıklarına maruz kalmış kişilerin fark ettiği yetersizlik etkilerini tanımlamak üzere kullanılmaktadır. $^{2-6}$ Envanterin orjinal adında geçen "dizziness" sözcüğünün Türkçesi "baş dönmesi" olarak ifade edilse de tıbbi açıdan farklı etyolojik nedenleri tanımlayabilmektedir. KBB disiplininde bu belirsizliği karşılamak amacıyla pseudovertigo tanımı kullanılmaktadır. $^{7}$

Literatür tarandığında BEE'nin Türkiye'de yapılan ilgili araştırmalarda güvenilirlik ve geçerlilik çalışmaları yapılmadan orijinal versiyonu kaynak gösterilerek kullanıldığı saptanmıştır. ${ }^{8,9} \mathrm{Bu}$ çalışma, envanterin Türkçe geçerlilik ve güvenirlilik çalışmasının yapıldığı ilk çalı̧̧madır.

\section{GEREC VE YÖNTEM}

\section{Araştırmanın Türü}

$\mathrm{Bu}$ araştırma metodolojik bir araştırmadır.

\section{Araştırmanın Evreni ve Örneklemi}

BEE'nin Türkçeye uyarlanması için envanteri geliştiren Craig W. Newman'dan yazılı onay alınmıştır. Turgut Özal Üniversitesi Tip Fakültesi Etik Kurul onayından sonra (31.10.2014, 99950669/371) Kasım 2014 - Şubat 2015 tarihleri arasında çalışma yürütülmüştür. Turgut Özal Üniversitesi Tıp Fakültesi Hastanesi Nöroloji, Kulak Burun Boğaz ve Aile Hekimliği Polikliniklerine en az son bir aydır devam eden baş dönmesi yakınması ile başvuran hastalar arasından gönüllü onamları alınanlar çalışmaya dahil edilmiştir. Hastalarda eşlik eden mental- muskuloskeletal, herhangi bir kronik sistemik hastalığın olmaması veya bir tedavi almıyor olması kıstası aranmıştır. Ayrıca Türkçeyi anlayıp konuşabilenler ve günlük yaşam aktivitelerini bağımsız olarak yapabilecek düzeyde olanlar çalışmaya alınmıştır. Baş dönmesi yakınmasına yönelik olarak ilaç kullanmakta olan hastalar çalışma dişı tutulmuştur. Örneklem sayısının envanter madde sayısının 3-10 katı olacak biçimde olmasının uygun olduğu belirtilmektedir. ${ }^{10}$ İstatistiksel olarak örneklem grubunu en iyi yansitacak olan 82 erkek (\%46), 96 kadın (\%54) olmak üzere 178 hastaya ulaşılmıştır. Baş dönmesi yakınması ile başvuran olgularda envanter hastalara verilmeden önce çalışma hakkında bilgilendirme yapılmış ve hastaların onamları alınmıştır. Envanterin doldurulması yaklaşık on dakika sürmüştür.

\section{Veri Toplama Araçları}

\section{Yarı Yapılandırılmış Görüşme Formu}

Hastaların sosyodemografik özellikleri, başvuru nedeni ve tıbbi tanısına ilişkin bilgileri içermektedir. Hastanın yaşı, cinsiyeti, çalışma durumu, eğitim durumu ve medeni durumu sorulmuştur.

\section{Baş Dönmesi Engellilik Envanteri}

Baş Dönmesi Engellilik Envanteri (BEE), 1990 y1lında Jacobson ve Newman tarafından geliştirilmiştir. BEE, hastaların baş dönmesi ve denge bozukluğunu ağırlaştıran faktörlerin yanı sıra vestibüler sistem hastalıklarında duyusal ve fonksiyonel sonuçları belirleyen 25 maddeden oluşmaktadır. $^{7} \quad$ Alt envanterler vestibüler sistem hastalıklarının fiziksel, duyusal ve fonksiyonel etkilerini belirlemeye yöneliktir. $1,4,8,11,13,17$ ve 25 . sorular fiziksel engelliliğii $2,9,10,15,18,20,21,22$ ve 23 . sorular duygusal engelliği; $3,5,6,7,12,14,16,19$ ve 24 . sorular ise fonksiyonel engelliliği ölçmek üzere yapılandırılmıştır. Her soru, evet (4 puan), hayir (0 puan) ve bazen (2) cevaplarından oluşmaktadır. Envanterin alt birimlerinin puanlanmasında 28 puan fiziksel engelliliği, 36 puan fonksiyonel ve duyusal engelliliği belirlemek için sınır olarak önerilmiştir. Yüksek puanlar hastanın baş dönmesi yakınmasının ileri düzeyde yaşamını engellediği yönünde yorumlanmaktadır.

\section{Dil Uyarlaması}

Envanterin İngilizce'den Türkçe'ye çevirisi ilk olarak araştırmacı yazarlar tarafından yapılmıştır. Bu çeviri Turgut Özal Üniversitesi Yabanc1 Diller Okulu'ndan bir öğretim üyesi tarafından orijinaline benzerliği açısından değerlendirilmiş ve bazı değişiklikler ölçeğe eklenmiştir. Çeviri metni; Türkçe dil kuralları ve anlam bütünlüğü açısından Türk Dili ve Edebiyatı alanında yetkin bir öğretim üyesi tarafından değerlendirilmiştir. Envanterdeki soruların anlaşılırlığını ölçmek amacıyla Turgut Özal Üniversitesi Tip Fakültesi Hastanesi Aile Hekimliği 
Polikliniğine herhangi bir yakınmayla başvuran on kişi ile ön deneme gerçekleştirilmiştir.

\begin{tabular}{|c|c|c|c|}
\hline Bileşenler & Özdeğer & $\begin{array}{c}\text { Açıklanan Var. } \\
\%\end{array}$ & Toplam \% \\
\hline 1 & 7,12 & 28,48 & 28,48 \\
\hline 2 & 1,99 & 7,96 & 36,44 \\
\hline 3 & 1,44 & 5,77 & 42,21 \\
\hline
\end{tabular}

\section{Verilerin Değerlendirilmesi}

Verilerin değerlendirilmesi sırasında SPSS 16,0 (SPSS Inc., Chicago, IL, USA) sürümü kullanılmıştır. Verilerin istatistiksel değerlendirilmesinde, puanların tutarlılık derecesi, test-tekrar test analizi, iç tutarlılık analizi için Cronbach Alpha Katsayısı, Bartlet testi, açımlayıcı faktör analizi, doğrulayıcı faktör analizi kullanılmıştır.

\section{BULGULAR}

Çalışmaya katılan 178 bireyin 104 'ü $(\% 58,5)$ eğitim düzeyi yüksekokul mezunu ve daha üzeri; 146's1 $(\% 82,1)$ evli ve 121'i (\%68) çalışandır. Çalışmaya alınanların yaş ortalaması 36,6 bulunmuştur (en düşük 19, en yüksek 46).

\section{Baş Dönmesi Engellilik Ölçeğinin Geçerliğine İlişkin Bulgular}

Kapsam Geçerliği: Baş Dönmesi Engellilik Envanterinin İngilizceden Türkçeye çevrilmesinden sonra iki aile hekimliği uzmanı, iki KBB uzmanı ve iki nöroloji uzmanı tarafindan envanter içeriği değerlendirilmiştir. Uzmanlardan envanterde yer alan her bir soru için baş dönmesi yakınmasını ne derecede ilgilendirdiği ve ölçtüğü konusunda; çok uygun, uygun fakat ufak değişiklikler gerekir, uygun hale getirilmesi gerekir, uygun değil seçeneklerini, oluşturulan form üzerinde işaretlemeleri istenmiştir. Değerlendirme sonucunda uzmanlar arasında Kendall W analizi sonucuna göre istatistiksel olarak farklılık olmadığı, uzmanların envanterin kapsam içeriği konusunda hemfikir oldukları görülmüştür.

Yapı Geçerliği: Yap1 geçerliğini belirlemek amacıyla yapılan Bartlett testine göre ki-kare değerinin anlamlı (kikare $=1442,511 ; \quad \mathrm{p}=0,001)$ olduğu saptanmıştır. Aynı zamanda KMO (Kaiser-Meyer-Olkin) değerinin yüksek olduğu $(0,837)$ belirlenmiştir. Bu veriler temel alınarak faktör analizi yapılmıştır. Öz değerleri 1.00'ın üzerinde üç bileşenin olduğu ve bunun da envanterin üç faktörlü bir yapıya sahip olduğu saptanmıştır. Tablodan da anlaşılacağı üzere birinci bileşene ait özdeğer 7,12, ikincisinde 1,99 ve üçüncüsünde ise 1,44 olarak hesaplanmıştır. Elde edilen bu sonuçlar Baş dönmesi Engellilik Envanteri'nin üç boyutlu olduğuna işaret etmektedir. Envanterin üç faktörü toplam değişkenliğin \%42,27'sini açıklamaktadır (Tablo 1).

\section{Baş Dönmesi Engellilik Ölçeğinin Güvenirliğine İlişkin Bulgular}

Madde Analizi: Madde analizinde ayırıcılık gücü indeksi için madde-test korelasyonu hesaplanmıştır. Her üç faktörde yer alan her bir maddenin oldukça yüksek maddeenvanter korelasyonu olduğu saptanmıştır. Fiziksel Engellilik boyutu için en düşük madde-envanter korelasyonunun 0,27 ile dördüncü maddede ve en yüksek ise 0,54 ile on birinci maddede olduğu anlaşılmaktadır. Duygusal Engellilik boyutu için en düşük madde-envanter korelasyonunun on beşinci maddede $(0,24)$, en yüksek yirminci maddede $(0,68)$ olduğu görülmektedir. Son olarak Fonksiyonel Engellilik boyutu için en düşük maddeenvanter korelasyonu 0,27 ile on dördüncü, en yüksek madde-envanter korelasyonu 0,53 ile 19. maddededir. Her üç boyuta ilişkin olarak toplam varyansın açıklanma yüzdesi \%42 olarak belirlenmiştir (Tablo 2).

\begin{tabular}{|c|c|c|c|c|c|}
\hline \multicolumn{4}{|c|}{$\begin{array}{l}\text { Tablo 2. Baş Dönmesi } \text { Engellili } \\
\text { maddelerin madde-test korelasyonlar }\end{array}$} & \multicolumn{2}{|c|}{ Envanterindeki } \\
\hline \multicolumn{2}{|c|}{ Fiziksel } & \multicolumn{2}{|c|}{ Duygusal } & \multicolumn{2}{|c|}{ Fonksiyonel } \\
\hline \multicolumn{2}{|c|}{ Engellilik } & \multicolumn{2}{|c|}{ Engellilik } & \multicolumn{2}{|c|}{ Engellilik } \\
\hline \multicolumn{2}{|c|}{ Cronbach Alpha } & \multicolumn{2}{|c|}{ Cronbach Alpha } & \multicolumn{2}{|c|}{ Cronbach Alpha } \\
\hline \multicolumn{2}{|c|}{0,672} & \multicolumn{2}{|c|}{0,817} & \multicolumn{2}{|c|}{0,725} \\
\hline $\begin{array}{c}\text { Madde } \\
\text { No }\end{array}$ & $\begin{array}{l}\text { Madde- } \\
\text { envanter }\end{array}$ & $\begin{array}{c}\text { Madde } \\
\text { No }\end{array}$ & $\begin{array}{l}\text { Madde- } \\
\text { envanter }\end{array}$ & $\begin{array}{c}\text { Madde } \\
\text { No }\end{array}$ & $\begin{array}{l}\text { Madde- } \\
\text { envanter }\end{array}$ \\
\hline s1 & 0,42 & s2 & 0,39 & s3 & 0,38 \\
\hline s4 & 0,27 & s9 & 0,57 & s5 & 0,41 \\
\hline s8 & 0,31 & $\mathrm{~s} 10$ & 0,59 & s6 & 0,52 \\
\hline s11 & 0,54 & s15 & 0,24 & s7 & 0,52 \\
\hline s13 & 0,38 & s18 & 0,42 & $\mathrm{~s} 12$ & 0,35 \\
\hline s17 & 0,33 & s20 & 0,67 & s14 & 0,27 \\
\hline \multirow[t]{3}{*}{ s25 } & 0,47 & s21 & 0,61 & s16 & 0,47 \\
\hline & & s22 & 0,56 & s19 & 0,53 \\
\hline & & s23 & 0,57 & s24 & 0,46 \\
\hline
\end{tabular}

Envanterin belirlenen boyutlarının doğrulanması için doğrulayıcı faktör analizinden yararlanılmıştır. Envanterin doğrulayıcı faktör analizine ilişkin standartlaştırılmış çözümleme değerlerinin 0,30 üzerinde olduğu görülmüştür. Gizil değişkenlerin gözlenen değişkeni açıklama durumlarına ilişkin $t$ değerlerinin 0,05 ve 0,01 düzeyinde istatistiksel olarak anlamlı olmadığı gözlenmiştir (Şekil 1). 


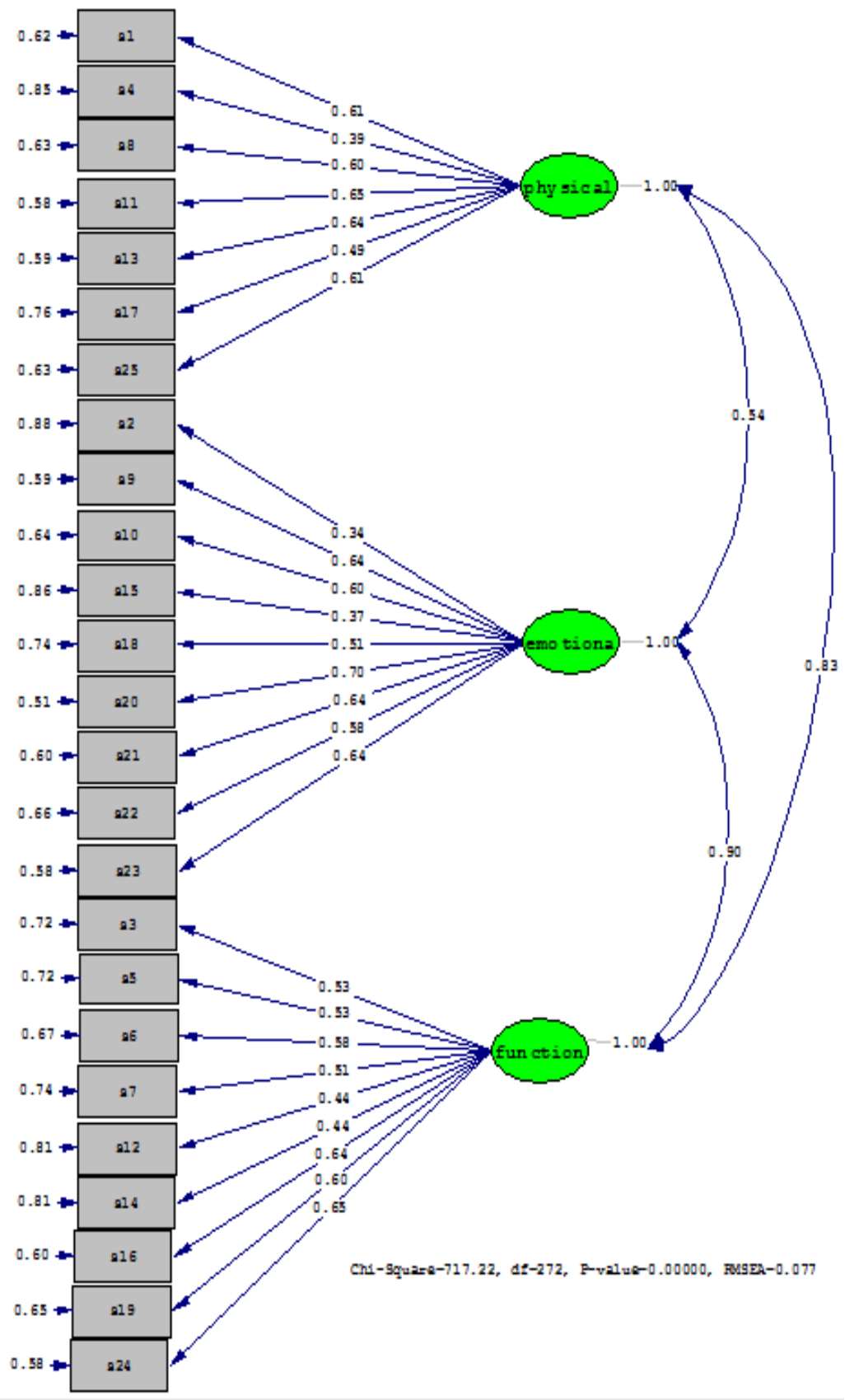

Şekil 1. Baş Dönmesi Engellilik Envanterinin sorularına uygulanan doğrulayıcı faktör analizi diyagramı

Tablo 3. Baş Dönmesi Engellilik Envanterinin Uyum Iyiliği Testlerine (Goodness-of-Fit Indices) ilişkin değerleri

\begin{tabular}{lllllllllll}
\hline Model & $\aleph^{2}$ & Sd & $\aleph^{2} / \mathrm{sd}$ & $\mathrm{P}$ & AGFI & GFI & CFI & NFI & SRMR & RMSEA \\
\hline $\begin{array}{l}\text { Kavramsal } \\
\text { model }\end{array}$ & 717,22 & 272 & 2,63 & 0,00 & 0,79 & 0,83 & 0,94 & 0,90 & 0,074 & 0,07 \\
\hline
\end{tabular}


İç Tutarlılık: Envanterin güvenirlilik çalışması için, envanterden alınan puanların tutarlılık derecesi ve envanterin homojenliğini belirlemek amacıyla test-tekrar test analizi yapılmış ve envanteri oluşturan maddelerin iç tutarlılığını veren Cronbach alpha katsayısı hesaplanmıştır. Envanterin geçerlik ve güvenirlilik çalışmasını yapabilmek amacıyla araştırma kapsamına giren öğrencilerden elde edilen veriler iki gruba ayrılmıştır. İlk gruba açımlayıcı faktör analizi, ikinci gruba da doğrulayıcı faktör analizi yapılmıştır. Faktör analizi yapılırken öncelikle Bartlett testi yapılmış ve örneklem büyüklüğünün faktör analizi için uygun olup olmadığına bakılmıştır. Bartlett testi verilerine dayalı olarak açımlayıcı faktör analizi (döndürülmüş) yapılmıştır. Faktör analizine alınan değişkenlerin (maddelerin) kaç faktörde toplandığını belirlemek amacıyla öncelikle öz değerlere ve açılanan yüzdelere bakılmıştır. Son olarak doğrulayıcı faktör analizi yapılmıştır.

\section{TARTIȘMA}

Bir envanterin uyarlanmasında, dil uyarlaması sonrasında, geçerlilik ve güvenilirliğinin test edilmesi gerekmektedir. Bu çalışmada Baş Dönmesi Engellilik Envanterinin geçerli olup olmadığı faktör analizi ve kapsam (içerik) geçerliği ile güvenilir olup olmadığı ise madde-toplam puan korelasyonu ve iç tutarlılık yöntemleri ile değerlendirilmiştir. Yukarıda özetlenen bulgular, Türkçeye uyarlaması yapılmış olan Baş Dönmesi Engellilik Envanterinin benzer popülasyonlar üzerinde yapılacak araştırmalarda üç boyutlu yapısının geçerli ve güvenilir bir ölçüm aracı olarak kullanılabileceğine işaret etmektedir. Tüm alt envanterlerin iç güvenirlikleri yüksektir ve Cronbach alfa değerleri 0,67 ile 0,82 arasında değişmektedir. Burada görülen bir diğer önemli bulgu envanterin genelinde olduğu gibi alt envanter gruplarından elde edilen Cronbach alfa değerlerindeki paralellik olmuştur. $\mathrm{Bu}$ bulgu envanterin güvenilirliğini desteklemektedir.

Baş dönmesi nedeniyle hastaların önemli bir kısmı tıbbi tedaviye ihtiyaç duymakta, günlük aktivite ve iş kaybına uğramaktadırlar. ${ }^{11}$ Baş dönmesi insidansını \%3,1; yaşam boyu görülme sıklığını ise \% 22,9 olarak bildiren yayınlar mevcuttur. ${ }^{12}$ Akut baş dönmesi yakınması ile birinci, ikinci ve üçüncü basamaklarda değerlendirilen hastaların tanı ve

tedavi sürecinde laboratuvar ve görüntüleme yöntemleri gibi girişimlerin hasta ve geri ödeme sistemi üzerinde oldukça maliyetli olduğu bilinmektedir. ${ }^{11}$ Baș dönmesine neden olabilecek farklı hastalıkların ayırt edilmesi, tedavisinin planlanması ve neden olduğu hastalık yükünün değerlendirilmesi gerekmektedir.

Hastalık belirtileri hekimlerin tanı, tedavi ve takip sürecini başlatacak zincirin ilk halkasıdır. Baş dönmesi yakınması olan hastaların tanı, tedavi ve takipleri özel bakım ve bilgi gerektirmektedir. Baş dönmesi birçok hastalıkla birlikte görüldüğü zaman hastalığın karakteristiği, dalgalanma dönemleri önemli oranda değişiklik gösterebilmektedir. ${ }^{13}$ Baş dönmesi olan hastalar vertigo, sersemlik, presenkop ve dengesizlik yakınmaları ön planda olmak üzere dört farklı şekilde birinci basamağa başvurmaktadır. $\mathrm{Bu}$ hastaların üçte birinde vertigo yakınması ön plandadır. ${ }^{14}$ Sebebi ve karakteristiği her ne olursa olsun hastaların günlük yaşamlarına olan etkisi oldukça önemlidir. ${ }^{15}$

Bütüncül bir yaklaşım içinde öncelikle yaşlı bireyler olmak üzere tüm yaş gruplarında baş dönmesi belirtisinin hastalar açısından nasıl algılandığının objektif olarak ölçülmesi hasta takiplerinde önem arz etmektedir. ${ }^{16}$ Baş Dönmesi Engellilik Envanteri büyük oranda periferal ve santral vestibüler patolojisi olan hastalarda aynı zamanda travmatik beyin hasarı, ilerleyici baş boyun travma hastalarında ve majör anksiyetede subjektif baş dönmesi etkilerinin hayat kalitesi üzerine olan etkilerini belirlemekte kullanılmaktadır. $^{7}$

Birinci basamakta Türkiye'de geçerlilik güvenirlilik çalışması yapılmış, baş dönmesi engellilik düzeyinin değerlendirileceği bir envanter bulunmamasından yola çıkılarak yapılan bu çalışmada Baş Dönmesi Engellilik Envanterinin Türkçe formunun güvenilir ve geçerli olduğu saptanmıştır. Baş Dönmesi Engellilik Envanteri, klinisyenlerin uyguladıkları tedavinin etkinliğini saptamada, hastanın izlenmesi ve yaşam kalitesinde meydana getirdiği gelişmelerin tanımlamasında kullanılabilecek, hızlı ve kolay bir envanterdir. Bunun yanı sıra birinci basamak uygulamalarında aile hekimliği pratiğinde tedavinin değerlendirilmesi ve hasta takibinde yararlı olacağı kanaatindeyiz.

\section{Teșekkür}

Çalışmanın geçerlilik güvenilirlik analizlerini yapan Ankara Üniversitesi Sağlık Bilimleri Fakültesi Sosyal Hizmet bölümü öğretim üyesi Prof. Dr. Veli Duyan'a katkılarından dolayı teşekkür ederiz.

\section{KAYNAKLAR}

1. Rakel RE, Rakel D. The family physician. Textbook of Family Practice: Philadelphia: W.B; 2011:160-164.

2. Perez N, Garmendia I, Martin E, Garcia-Tapia R. Cultural adaptation of 2 questionnaires for health measurement in patients with vertigo. Acta Otorrinolaringol Esp 2000;51(7):572-80.

3. Kurre A, Van Gool C, Bastiaenen C, Gloor-Juzi T, Straumann D, Bruin E. Translation, cross-cultural adaptation and reliability of the german version of the dizziness handicap inventory. Otol Neurotol 2009;30(3):359-67.

4. Nyabenda A, Briart C, Deggouj N, Gersdorff M. Normative study and reliability of French version of 
the dizziness handicap inventory.: Ann Readapt Med Phys 2004;47(3): 105-13.

5. Goto F, Tsutsumi T, Ogawa K. The Japanese version of the Dizziness Handicap Inventory as an index of treatment success: exploratory factor analysis. Acta Otolaryngol 2011;131(8):817-25.

6. Poon D, Chow L, Au D, Hui Y, Leung M. Translation of the dizziness handicap inventory into Chinese, validation of it, and evaluation of the quality of life of patients with chronic dizziness. Ann Otol Rhinol Laryngol 2004;113:1006-11.

7. Jacobson G, Newman C. The development of the Dizziness Handicap Inventory. Arch Otolaryngol Head Neck Surg 1990;11(4):424-7.

8. Tümkaya F, Ardıç FN, Tümkaya S, Kara CO, Geriatrik Vertigolu Hastalarda Etyolojik Dağılımın Psikojenik Semptomlar ve İşlev Kayıpları İle İlişkisinin Değerlendirilmesi KBB-Forum 2014;13(1):13-18.

9. Dönmez B, Akdal G. Vestibular Rehabilitation In Unilateral Peripheral Vestibulopathy: A Preliminary Report. Journal of Neurological Sciences [Turkish] 2008;5:(2)15;128-135.

10. Sencan H. Factor analysis and reliability. Ankara: Seçkin Yayıncılık; 2005:355-414

11. Neuhauser H, Von Brevern M, Radtke A, Lezius F, Feldmann M, Ziese T, et al. Epidemiology of vestibular vertigo: a neurotologic survey of the general population. Neurology 2005;65(6):898-904.

12. Neuhauser H, Radtke A, Von Brevern M, Lezius F, Feldmann M, Lempert T. Burden of dizziness and vertigo in the community. Arch Intern Med 2008;168(19):2118.

13. Post R, Dickerson L. Dizziness: A Diagnostic Approach. Am Fam Physician 2010;82(4):361-8.

14. Yayla ME. Birinci Basamakta Başdönmesi Ayırıcı Tanıs1. Ankara Med J 2014; 14(2): 59-64.

15. Ardiç FN, Topuz B, Kara CO. Impact of multiple etiology on dizziness handicap. Otol Neurotol 2006;27(5):676-80.

16. Tinetti ME, Gill TM. Dizziness among older adults: a possible geriatric syndrome. Ann Intern Med 2000;132(5):337-44. 